NBER WORKING PAPER SERIES

\title{
CIGARETTES AND ALCOHOL: SUBSTITUTES OR COMPLEMENTS?
}

\author{
Sandra L. Decker \\ Amy Ellen Schwartz \\ Working Paper 7535 \\ http://www.nber.org/papers/w7535
NATIONAL BUREAU OF ECONOMIC RESEARCH
1050 Massachusetts Avenue
Cambridge, MA 02138
February 2000

We would like to thank Michael Grossman, Robert Kaestner and participants at the American Economic Association and the National Bureau of Economic Research Summer Institute meetings for helpful comments. We also gratefully acknowledge financial support from the Robert Wood Johnson Foundation's Substance Abuse Policy Research Program. The analyses, interpretations and conclusions contained in this paper are those of the authors and do not necessarily reflect the opinions of the Centers for Disease Control and Prevention, the original source of the Behavioral Risk Factor Surveillance System data. The views expressed herein are those of the authors and not necessarily those of the National Bureau of Economic Research.

(C) 2000 by Sandra L. Decker and Amy Ellen Schwartz. All rights reserved. Short sections of text, not to exceed two paragraphs, may be quoted without explicit permission provided that full credit, including (C) notice, is given to the source. 
Cigarettes and Alcohol: Substitutes or Complements?

Sandra L. Decker and Amy Ellen Schwartz

NBER Working Paper No. 7535

February 2000

JEL No. H20

\begin{abstract}
Taxation of cigarettes and alcohol can raise revenue and reduce consumption of goods with negative external effects. Despite medical and psychological evidence linking their consumption, little previous work has investigated the significance of cross-price effects in cigarette and alcohol consumption. We use individual-level data from the Behavioral Risk Factor Surveillance System to investigate cigarette and alcohol consumption in the US, estimating both own and cross-price elasticities. Results suggest significant cross-price effects. Specifically, we find that higher alcohol prices decrease both alcohol consumption and smoking participation (suggesting a complementarity in consumption), while higher cigarette prices tend to decrease smoking participation but increase drinking. The significance of these findings suggests that further work is warranted to better understand the social and economic relationship between cigarette and alcohol consumption.
\end{abstract}

Sandra L. Decker

Wagner School of Public Service

New York University

$40 \mathrm{~W} .4^{\text {th }}$ Street, Room 602

New York, NY 10012

and NBER

sandra.decker@nyu.edu
Amy Ellen Schwartz

Wagner School of Public Service

New York University

4 Washington Square North

New York, NY 10003

amy.schwartz@nyu.edu 


\section{Introduction}

Despite abundant evidence documenting the deleterious effects of smoking, and more than three decades of government policy and advertising aimed at reducing smoking, cigarette smoking is still one of the most important causes of preventable death (Bien and Burge [1990]). Although increases in the drinking age and the strengthening of laws surrounding driving under the influence (DUI) have reduced the number of alcohol-related deaths, excessive alcohol consumption also continues to create a wide range of personal and social problems including damage to the liver and pancreas, brain dysfunction, cardiovascular problems, birth defects, suicide, family violence, and accidental fatalities due to DUI. (See Kenkel [1993] for a fuller discussion). Recently, policy-makers have turned to tax policy in an effort to simultaneously gain tax revenue, curtail consumptipn and "internalize" the externalities imposed by consumers of alcohol and tobacco on the rest of society. ${ }^{1}$ Clearly, both the excess burden and the efficacy of such tax policy depend on the price elasticity of demand for cigarettes and alcohol and the interdependence of their demands. While there has been much previous work investigating the demand for cigarettes and alcohol, all but a handful have examined these separately (two notable exceptions, discussed below, are Jones [1989] and Goel and Morey [1995]). ${ }^{2}$ This paper adds to the limited econometric literature investigating the substitutability (or complementarity) between cigarettes and alcohol.

Understanding the connections between the consumption of alcohol and cigarettes and incorporating their interrelationship into econometric consumption analyses is important for two reasons. First, if alcohol and cigarettes are important substitutes (or complements), then correctly specified cigarette demand equations must include prices of alcoholic beverages and relevant policy variables as well. Similarly, alcohol equations should include cigarette prices and relevant policies. Otherwise, the estimated coefficients

1 Cordes, Nicholson, and Sammartino [1990] provide a useful overview of the advantages and difficulties of taxing alcohol and cigarettes to control social costs while raising revenues.

2 A nother exception, Browning [1987], looks at smoking and drinking in a single life-cycle model, however, the empirical work presented does not allow for substitutability or complementarity between alcohol and tobacco. Viscusi [1992] and L eung and Phelps [1993] provide a review of the literature on the demand for cigarettes and alcohol, respectively. 
of the included variables may be biased, depending, as usual, on the relationship between the included and excluded variables. As an example, if cigarettes and alcohol are complements and their prices are positively correlated, then a cigarette demand equation that omits the price of alcohol as an explanatory variable will yield upwardly biased estimates of the price elasticity. Thus, the efficacy of taxation in reducing consumption of cigarettes may be overestimated and the revenue raising potential underestimated.

Second, if a policy has a "cross" effect on some other market, any analysis of the relative merits of the policy must include the cross effect to provide useful policy guidance. For example, increasing the drinking age may decrease teenage drinking, but may also have the side benefit of decreasing teen smoking. To the extent that this effect is significant, making good policy recommendations regarding the increased drinking age would require considering these cross impacts. Alternatively, as is well known in the tax literature, setting efficient tax rates requires more than just an unbiased estimate of the own-price elasticity. Instead, since the excess burden of a tax on cigarettes depends upon the cross price elasticities of all goods with which it is related, knowledge of the cross-price effects is critical to efficient taxation. ${ }^{3}$

There is a growing body of evidence from medical researchers suggesting that alcohol and cigarette consumption are related, due to a wide range of biological and psychological factors. ${ }^{4}$ Researchers point to studies such as Walton [1972] (which found that 97 percent of a sample of male inpatient alcoholics were smokers) as support for the theory that smoking and drinking reflect a common addictive personality pattern. ${ }^{5}$ An alternative explanation is that smoking and drinking may serve to satisfy an "oral drive". Interestingly, while this suggests that drinkers are more likely to be smokers and vice versa, increased

${ }^{3}$ The theory of the second best tells us: "In the presence of existing distortions, policies that in isolation would increase efficiency can decrease it and vice versa" (Rosen [1995], p.326). For a two good case, the overall excess burden depends upon the own-price elasticities of each of the goods, and their cross-price elasticity, in addition to their prices and current tax rates.

${ }^{4}$ Bien and Burge [1990] summarize recent literature.

${ }^{5}$ In another study, Bobo, Gilchrist, Schilling, N oach and Schinke [1987] reported that 92.3 percent of the staff interviewed in an alcohol treatment facility estimated that 75 to 100 per cent of the patients smoked. Some researchers, such as Craig and V an N atta [1977], go so far as to suggest that nonsmoking alcoholics may represent a subcategory in which alcoholism should be considered secondary to some other psychiatric diagnosis. 
drinking may mean decreased smoking among smokers and drinkers (i.e. substitutability) and/or quitting smoking (or drinking) may increase participation in the substitute vice. Third are the "learning based explanations" - smoking and drinking may serve as mutual cues, one setting the occasion for use of the other, or each may be triggered by the same situational factors. Sitting in a bar having a drink may, for example, trigger smoking. Finally, the relationship may derive from pharmacological factors, since the combined use of alcohol and nicotine may be due to a mutual augmentation of effects. A lternatively, since alcohol is a depressant while nicotine is a stimulant, cigarettes and alcohol may be used to balance each other out.

Two recent econometric studies have looked at the interdependence of cigarette and alcohol consumption, with conflicting results. Goel and M orey [1995] use a panel of U.S. state-level data for 1959-1982 to estimate both cigarette and liquor consumption equations. They find that cigarettes and liquor are substitutes in consumption, with an estimated cross price elasticity of demand for cigarettes with respect to the price of liquor of 0.100 and an estimated cross price elasticity of demand for liquor with respect to the price of cigarettes of 0.332 . In contrast, Jones [1989] estimates budget share equations for four categories of alcoholic drinks and for tobacco using aggregate quarterly expenditure data for the U.K. for 1964-1983. Jones finds tobacco to be a complement to all four categories of alcohol. The strongest complementarity is found between tobacco and spirits, having an estimated cross price elasticity of -2.31 .

Although the Goel and M orey analysis also benefits from the use of (state-level) panel data, Jones is econometrically more sophisticated and the finding of overall complementarity between liquor and cigarette consumption seems more persuasive than Goel and M orey's finding of substitutability. Goel and M orey's use of both lagged consumption and state effects essentially yields reduced form growth equations, which seem difficult to interpret. This strategy may account for the implausibility of some of their results. Although their estimated own price elasticity of cigarette consumption is similar in magnitude to that found elsewhere, their estimated own price elasticity of liquor consumption of 0.130 is much smaller than that found here and elsewhere. Also, although they note that their estimated income elasticity of demand of liquor (of 0.92 ) is in the range of the literature, they do not offer an explanation for their estimated income elasticity of cigarette consumption of 0.312 (indicating 
that cigarettes are a normal good), which is opposite in sign to what is consistently found el sewhere in the literature. Finally, although Goel and M orey reject exogeneity of prices, they do not give motivation for this difference from the standard approach, and in fact use an unspecified list instrumental variables to correct for endogeneity. Our own work here builds upon the Jones work by using individual-level data allowing for a more explicit modeling of both the participation and consumption decisions, and allowing us to test the consistency of the data with the assumption and imposition of symmetric cross effects.

Specifically, we use data for 474,096 individuals from 45 states in the US between 1985 and 1993 from the Behavioral Risk Factor Surveillance System (BRFSS). We inyestigate the demand for alcohol and cigarettes, and estimate both own and cross price elasticities of demand. ${ }^{6}$ Our analysis differs from the previous work cited above in that we use individual rather than aggregate-level data. This has the advantage of avoiding the bias (away from zero) in aggregate analyses that derive from using sales figures based on taxes paid as the measure of aggregate consumption. Although sales figures are reliable, they do not adequately reflect actual consumption in each state, because there is considerable smuggling or bootlegging of cigarettes across jurisdictions. ${ }^{7}$ In addition, as mentioned, using individual data allows us to examine both prevalence and conditional demand separately (by estimating separate participation and consumption equations) and to perform separate subgroup analyses for women and men.

The next section of the paper outlines the analytical framework for our work. Section III describes our data set and section IV our results. A final section concludes.

\section{Analytical Framework}

${ }^{6}$ We follow much of the previous work in this area and use the after-tax price of cigarettes and beer in our work, rather than investigating taxes and prices separately. While using both variables is appealing, interstate differentials in the after-tax price of cigarettes are driven largely by tax differences and deriving reasonable state-level alcohol tax rates is problematic.

7 See Lewit and Coate [1982] for a fuller discussion of the advantages of using individual data in estimating the own price elasticity of cigarettes. 
Our work employs a standard demand model of alcohol and cigarette consumption. We assume individual utility depends upon consumption of "addictive" goods - cigarettes and alcohol - as well as other consumption goods. M aximizing utility subject to a suitable budget constraint yields individual demand as a function of the prices of both cigarettes and alcohol, income, and other individual characteristics. Specifically, we estimate a function of the following form:

$$
Y^{k_{i j t}}=a+b P^{B_{j t}}+c P^{C}{ }_{j t}+d X_{i t}+e R j+f T t+e_{i j t}
$$

The dependent variable can be the amount smoked or the amount drank by the ith individual in the jth state in year $t$, or it can be a dichotomous variable indicating either whether the individual is a smoker or whether the individual is a drinker. Independent variables include the price of beer $\left(\mathrm{P}_{\mathrm{jt}}^{\mathrm{B}}\right)$ in state $\mathrm{j}$, the price of cigarettes in state $\mathrm{j}\left(\mathrm{P}_{\mathrm{jt}} \mathrm{C}^{\mathrm{C}}\right)$, a vector of individual characteristics $\left(\mathrm{X}_{\mathrm{it}}\right)$ including income, education, age, marital status and race, a set of region dummies $\left(R_{j}\right)$, a set of year dummies $(T t)$, and a random disturbance term (eijt). These variables are similar to those employed by previous researchers (such as L ewit and Coate [1982]) and have generally been found to be related to smoking and drinking behavior.

We estimate the demand for alcohol over all individuals (both drinkers and non-drinkers), the drinking participation decision, and the demand for alcohol among drinkers only. We do the same for cigarette consumption - estimate the demand for cigarettes over all individuals (both smokers and nonsmokers), the smoking participation decision and the demand for cigarettes among smokers only. ${ }^{8}$ We estimate linear versions of the equation first under the assumption that the cross price effects are zero in order to provide a comparison to previous studies of cigarette and alcohol consumption. We then estimate both the own and the cross price elasticities of demand. We perform separate analyses for women and men, following the observation of many previous researchers that the characteristics of demand for these groups differ.

\footnotetext{
${ }^{8}$ Note that we implicitly assume that the specified functions are demand curves, identified by variation in the supply curves across states. In addition, as mentioned above, we follow many previous authors and treat price as exogenous, since interstate price differentials largely reflect differences in excise taxes.
} 


\section{Data}

We use data on individual-level cigarette and alcohol consumption among adults from the Centers for Disease Control and Prevention's (CDC) Behavioral Risk Factor Surveillance System (BRFSS). Since 1981, the CDC has collaborated with state health departments to collect this data in order to track health behaviors related to premature causes of death. We use data from 1985 (when 23 states collected data) to 1993 (when all states except Wyoming participated in the survey). We exclude approximately 11 percent of the sample due to missing income information, yielding 474,096 observations on smoking and drinking behavior among adults. ${ }^{9}$ The survey is designed to be representative by state and is stratified by age, sex and race. ${ }^{10}$

This data set has not been widely used by economists or health policy analysts, yet has several distinct advantages including its large sample size, the availability of a set of consistent cross sections for nine years, and complete questions on cigarette and alcohol consumption as well as demographic attributes. Its particular advantage over the more commonly used $\mathrm{N}$ ational $\mathrm{H}$ ealth Interview Survey is that state identifiers are routinely publicly available. The primary disadvantage of the data set is that it is not a panel and therefore we do not have much information on an individual's use of cigarettes or alcohol in years prior to the survey year, which would allow us to investigate the importance of habit or addiction in consumption decisions. Thus _we estimate only short-term own and cross-price elasticities; the long-term elasticities would be larger. ${ }^{11}$

\footnotetext{
${ }^{9}$ We also exclude observations from New Jersey, the District of Columbia, Hawaii, M aine and Rhode Island due to missing information on the price of alcoholic beverages, as discussed below. Income in the BRFSS is reported in several categories up to $\$ 50,000$, although we take the midpoint of each category, and enter income as a continuous variable in the analysis. The proportion missing income information is very similar to that in the $\mathrm{N}$ ational Health Interview Survey. The propensity not to report income does not seem to vary significantly by age, sex and race.

${ }^{10}$ Because small states are over-represented relative to larger states and since the survey does slightly under-sample whites, men and younger adults, we have explored the use of sample weights in our estimation. We obtain results that are qualitatively similar to those presented here without weights.

${ }^{11}$ In particular, we are not able to estimate a "rational addiction" model. The rational addiction models of consumption (due to Becker and M urphy [1988] and others which followed) look at consumption as
} 
We match the BRFSS data to data measuring the average price of a pack of cigarettes by state and year, using data from retail surveys conducted by the Tobacco Institute [1994]. ${ }^{12}$ We also match the data on individual consumption of alcohol and cigarettes to a measure of the price of alcoholic beverages by state and year using information from the A merican Chamber of Commerce Researchers A ssociation (A CCRA) Inter-City Cost of Living Index (various years). ${ }^{13}$ ACCRA samples prices for many products among retailers in 240-280 "middle management" cities per quarter. We use information on the prices of goods in the third quarter of every year. Specifically, we use the price of beer as a proxy for the "average" price of beer, distilled spirits and wine, following Grossman, Chaloupka and Sirtalan (1998) and others. ${ }^{14}$ We estimate the state price of a six-pack of beer by weighting the prices in each city within the state by that city's estimated 1990 population, using information from the U.S. Department of Commerce's County and City Data Book, $1994 .{ }^{15}$ We deflate the price of a six-pack of beer by state and year both by ACCRA's

deriving from a rational decision made by individuals considering information on prices and other variables both now and in the future. These studies find larger price elasticities for cigarettes in the long run than in the short run, implying that increasing taxes will ultimately be more effective at reducing demand than short run results suggest. While we may be able to capture some of the longer-run elasticities by including lag and lead prices in our demand equations, we have very little information on consumption of cigarettes in years other than the survey year. We know only whether an individual ever smoked a cigarette, regardless of whether the individual smokes now. The exception is in 1991 and 1992, when the BRFSS included a question about the age at which an individual started smoking regularly.

12 This data reports the weighted average price (weighted according to purchase by the pack versus the carton) of a pack excluding sales taxes.

${ }^{13}$ As mentioned above, we exclude information from the BRFSS data on alcohol and cigarette consumption among individuals in New Jersey, the District of Columbia, Hawaii, Maine and Rhode Island, since ACCRA did not sample prices in these areas for many of the nine years we consider. The District of Columbia should be deleted from the sample in any case, since the percent of residents purchasing cigarettes in "bordering states" is presumably quite high.

${ }^{14}$ The price of beer in the ACCRA data is based on the price of a six-pack of Budweiser or Schlitz from 1985 to 1989, and on the price of a six-pack of Budweiser or M iller Lite from 1990 to 1993. The price excludes sales tax and deposit (if any). Chaloupka and Laxuthai [1997], in an investigation of the interdependence of alcohol and marijuana consumption, estimate a negative own price elasticity of alcohol using the beer price as a proxy for the price of all alcoholic beverages. They report that very similar estimates of the own price elasticity of demand for alcohol obtain using the beer price as using a weighted average of the prices of beer, wine and spirits.

15 Our analysis slightly underestimates elasticities as discussed in Lewit and Coate [1982], since some 
regional cost of living measure, and also by the overall Consumer Price Index to take account of general movements in prices over time. In general, since our estimates of the price of cigarettes and alcohol are based on suryey data with some measurement error, we expect our estimates of price elasticities to be biased down. ${ }^{16}$

Table 1 reports sample statistics on alcohol and cigarette consumption from the BRFSS data. As can be seen from the first column, approximately 50 percent of the sample has had an alcoholic beverage in the past month. Those who have had at least one alcoholic beverage had an average of roughly 21 drinks in the past month, yielding an average number of drinks consumed in the full sample of 10.7 per month among both "drinkers" and "non-drinkers". As can be seen from the last two columns of the top panel, men are more likely to have had a drink and also drink more than women. A pproximately 60 percent of men have had a drink in the past month compared to only 43 percent of women. $M$ ale drinkers have had an average of almost 29 drinks in the past month, while female drinkers have had an average of approximately 13 drinks.

The second panel of Table 1 describes cigarette consumption among those in our sample. A pproximately 25 percent of the adult population smokes. A mong smokers, the average amount smoked is about 18.5 cigarettes per day, or a little less than a pack. Smoking prevalence and amount smoked also differs somewhat between men and women. A pproximately 23.5 percent of women smoke compared to 26.7 percent of men, while female smokers smoke about 17 cigarettes per day compared to about 20 among male smokers. Overall, the number of cigarettes smoked per day per individual in the sample is about 4.6. We find that the magnitude of reported smoking is very similar in the BRFSS compared to other surveys of self-reported cigarette consumption, (e.g. L ewit and Coate [1982] using the $\mathrm{N}$ ational Health Interview Survey), and that the magnitude of reported drinking is also similar to other measures of self-reported

individuals in high tax states pay purchase cigarettes and alcohol in neighboring low tax states.

${ }^{16}$ We have performed our analysis using two different methods of aggregating the A CCRA data to the state level. Our estimates here are a simple weighted average of any city sampled by ACCRA in each year. U sing only a consistent set of cities sampled by state in each year yields, however, very similar estimates of the average price of beer by state and year, and does not significantly affect our analysis. 
alcohol consumption (Smith, Remington, Williamson and A nda [1990]).

Table 2 reports descriptive statistics for other characteristics of individuals in our sample. On average, a six-pack of beer costs approximately $\$ 2.77$, while a pack of cigarettes costs approximately $\$ 1.17$ per pack (both prices in 1984 dollars). A verage family income in the sample is about $\$ 23,000$, and the average age is 45. Focusing on the reference categories, approximately 57 percent of the sample is female, 85 percent is white, 17 percent lack a high school education, 57 percent are currently married, and 24 percent live in the W est.

Table 3 reports selected descriptive statistics over time. Since more states are participating in the BRFSS in every year, our sample size increases over time. As can be seen from this table, both alcohol and cigarette consumption have been falling over our sample period. ${ }^{17}$ The data show a slight fall in drinking participation over time, with a more substantial fall in average alcohol consumption among drinkers. ${ }^{18}$ While other researchers have reported that the elasticity of demand for cigarettes is higher among "not-yethooked" teenagers than it is among adults, the declining participation rate and consumption of cigarettes among adults reported here may reflect an increased propensity on the part of adults to quit or cut back, and not just decreased participation among youths.

As a check on the data, we compared our estimates of average cigarette consumption per individual in the BRFSS data to the average number of cigarettes sold in the U.S. per person over 18 per year using information on taxable withdrawals from the U.S. Bureau of Economic A nalysis' Survey of Current Business (various years). As reported elsewhere (e.g. Warner [1978]), we find that measures of cigarette consumption using self-reported data under-estimate actual cigarette consumption by about one-third. ${ }^{19}$ As

${ }^{17}$ Since average alcohol and cigarette consumption do not vary widely across states, the decrease in consumption over time is very similar if we consider only the 23 states originally participating in the BRFSS in 1985.

18 The drinking related questions in the BRFSS varied somewhat over the sample period. For example, prior to 1990, the survey included specific questions distinguishing the amounts of wine, beer and other liquor consumed. The change to a more general question in 1990 did generate some of the decrease in reported alcohol consumption between 1989 and 1990.

${ }^{19} \mathrm{Here}$, we actually overestimate the number of cigarettes sold per adult since the numerator includes some cigarettes sold to minors. We therefore exaggerate under-reporting of cigarette consumption among adults. 
in Wasserman, M anning, N ewhouse and W inkler [1991] as elsewhere, we assume that the amount of underreporting is not related to the amount smoked. Self-reported alcohol consumption is typically underreported by as much as 40 to 60 percent (M anning, Blumberg and M oulton [1995]). While Serdula, Williamson, Kendrick, A nda and Byers [1991] suggest there is also under-reporting of alcohol consumption in the BRFSS data, we assume that the amount of under-reporting is not related to the amount consumed.

Table 4 explores the positive correlation between drinking and smoking in the sample. As mentioned above, approximately 50 percent of the sample has had an alcoholic drink in the last month. A mong those who have had a drink, approximately 29 percent smoke compared to 21 percent who have not had a drink. Similarly, approximately 59 percent of smokers have had at least one drink, compared to 48 percent of nonsmokers. We believe that this positive correlation between cigarette and alcohol consumption is much stronger for heavy drinkers, a group we plan to analyze separately in future work.

\section{Results}

\section{a. Benchmark Analysis: Own Price Elasticity of Demand for Alcohol and Cigarettes}

Table 5 presents our preliminary results estimating the own price elasticity of demand for alcohol and cigarettes among all individuals in the sample. We use ordinary-least squares to estimate average alcohol and cigarette consumption as a function of own price, family income, several demographic variables, year and region effects. ${ }^{20}$ Considering first the demand for alcoholic beverages, we find similar relationships between the demographic variables and average alcohol consumption as found in much other work. Older, unmarried individuals and individuals with higher family income and some education consume more alcohol than others. M inorities and women consume less alcohol than others, all else equal. Turning to the cigarette demand equation, we find that adults with higher family income are less likely to smoke, older people are more likely to smoke, and minorities are less likely to smoke. Education is strongly negatively related to average cigarette consumption. Unmarried people are significantly more

\footnotetext{
${ }^{20}$ We do not find that our results here are sensitive to an alternative log-linear specification or to a Tobit specification accounting for censoring of observed alcohol and cigarette consumption at zero.
} 
likely to smoke than married people. Perhaps due to stress, divorced and separated people are also more likely to smoke relative to others. The year effects confirm that, all else equal, average alcohol and cigarette consumption among adults is falling strongly.

Finally, the own price elasticities of demand for alcohol and cigarettes are significantly negative. The coefficient on the price of alcohol indicates that a $\$ 1$ increase in the price of a six-pack of beer leads to about 3 fewer drinks consumed per month. U sing the mean price of a six-pack (\$2.77) and the mean consumption of alcoholic beverages (10.7), this implies that the estimated price elasticity of demand for alcohol is approximately -0.76 , which is, for example, very close to the estimated price elasticity of -0.80 found by M anning, Blumberg and M oulton [1995] using the $1983 \mathrm{~N}$ ational Health Interview Survey. The coefficient on the own price of cigarettes indicates that a $\$ 1$ increase in the price of a pack leads to about 1.4 fewer cigarettes smoked per day. U sing the mean price of a pack $(\$ 1.17)$ and the mean consumption of cigarettes (4.6), this implies that the estimated price elasticity of demand for cigarettes is approximately 0.36. This estimate is very close to those reported by others using individual-level data on cigarette consumption including Lewit and Coate [1982], Wasserman, M anning, N ewhouse and W inkler [1991], and Evans and Farrelly [1998], who find an elasticity of -0.35 using the $1987 \mathrm{~N}$ ational Health Interview Survey. ${ }^{21}$

The first set of columns in Table 6 summarizes the results from Table 5, while the second set uses state effects instead of region effects. Although many states have raised their tax rates on cigarettes at least once in recent years and a few states have raised tax rates on alcoholic beverages, we find that adding state effects renders the estimated own price elasticities indistinguishable from zero. We find, however, that the state effects are jointly significant $(F(44,474029)=37.09$ in the case of alcohol and $F(44,470028)=36.87$

${ }^{21}$ In an earlier specification, we interacted both the income and the price variables with the year effects to see whether income or price effects are changing monotonically overtime. As found in Wasserman et al. [1991], we found that cigarette consumption is becoming an increasing inferior good over time. Some have suggested that cigarette price elasticities fall over time as only the "hard core" smokers continue to smoke. U sing several years of data from the Health Interview Survey, Wasserman et. al find the opposite - i.e. that the price elasticity of demand for cigarettes became increasingly negative throughout the 1970s and 1980s. Wasserman et. al do, however, use a time trend and interact this trend with the price and income variables. We prefer using the more flexible specification here consisting of year effects, and find that price elasticities are slightly decreasing in absolute value over time. 
in the case of cigarettes). In fact, the large amount of previous work using individual-level data to estimate the price elasticity of demand for alcohol and cigarettes does not report using state effects, and in some cases, does not report using region effects. Since many policies (including, but not limited to, tax policies) are likely to vary across states, it is important to acknowledge that estimated elasticities are not robust to the inclusion of state effects. Since the variation in alcohol and cigarette prices over time within individual states is somewhat limited, using the cross-sectional variation in prices to investigate the price elasticity of cigarettes is desirable, and the estimates with state effects should be regarded as a lower bound. A useful direction for future research would explicitly consider state-level variables likely to affect alcohol and cigarette consumption (e.g. DUI and clean indoor air laws) instead of state effects. The remainder of the estimates presented here employ region effects only.

Since drinking and smoking behavior among women is significantly different from that among men, Table 7 presents estimates of the own price elasticity of demand for alcohol and cigarettes separately by sex. ${ }^{22}$ Comparing the bottom two panels of the table, we find that women are significantly more responsive to the price of alcohol but less responsive to the price of cigarettes. The highly elastic (-1.03) demand for alcohol among women is consistent with the notion that women (who, on average drink much less than men) may be more likely to be "casual" drinkers rather than the larger group of "regular and committed" drinkers among the men. We also find that women's demand for alcohol is much more income elastic than men's demand. In contrast, women tend to be less sensitive to the price of cigarettes than are men (elasticity of 0.32 versus -0.48 ). This is consistent with the lower price sensitivity among women found by Chaloupka [1992] and Lewit and Coate [1982] in the cigarette literature. We find that income is less strongly negatively related to cigarette consumption among women as compared to men and, although not reported here in the table, education is also less strongly negatively related to cigarette consumption among women. A lso not reported, we find that age is not such a strong predictor of cigarette consumption among women as it is for men and considering the year effects, find that cigarette consumption is not falling as strongly

\footnotetext{
${ }^{22}$ A $n$ F-test strongly rejects the appropriateness of pooling the two sexes $(F(25,474071)=213.50$ for alcohol and $F(25,470045)=213.52$ for cigarettes $)$.
} 
among women as among men, all else equal. Overall, our findings are consistent with the popular notion that smoking among young, educated women is up.

\section{b. Own and C ross Price E lasticities for Alcohol and Cigarettes}

Table 8 summarizes our findings on the elasticity of alcohol consumption with respect to both the own price of beer and the cross price of cigarettes. The first column considers average alcohol consumption among both drinkers and non-drinkers as in the first column of Table 7. Adding the cross price of cigarettes to the equation increases the magnitude of the own price elasticity of demand for alcohol from 0.76 to -.97 . The second two columns of Table 8 estimate a two-part model separately investigating drinking participation and average alcohol consumption among drinkers. The second column estimates drinking participation using a linear probability model. ${ }^{23}$ Comparing these columns, we find that the responsiveness of alcohol consumption to the own price of beer derives largely from price responsiveness in drinking participation (elasticity of -0.73 ), rather than in the amount consumed among drinkers (elasticity of -0.23), which is consistent with M anning, Blumberg and M oulton [1995]. Women's demand for alcohol is particularly price responsive, with a participation elasticity of -0.88 , and an elasticity of consumption among female drinkers of -0.31 .

In the second row of the table, we find that the cross price elasticity of alcohol consumption with respect to the price of cigarettes is positive, suggesting that alcohol and cigarettes are substitutes in consumption. The overall cross price elasticity of drinking with respect to the price of cigarettes is 0.50 , a sizeable effect which is about half as large as the own price effect. This positive cross price elasticity largely reflects changes in drinking participation (elasticity of 0.39 ) rather than changes in consumption among drinkers (elasticity of 0.12). A pparently, as cigarettes become more expensive, consumers cut back on cigarette consumption and "rely" instead on drinking participation. A gain, we find that women's drinking participation is more price responsive than men's (the cross price elasticity of participation is 0.52

\footnotetext{
${ }^{23}$ Results using a logit model are qualitatively quite similar to those reported here, indicating that heteroscedasticity is not extreme.
} 
for women compared to 0.27 for men), although men's amount consumed of alcohol is slightly more responsive to cigarette price than is demand among women.

Finally, looking at the income effects, the estimates indicate that alcohol is a normal good (with an income elasticity is 0.19 ) and that women's consumption is more responsive to income than is men's consumption. A gain, looking across the columns, we see that overall the income response derives largely from changes in participation rather than changes in consumption among drinkers.

Table 9 presents the results of estimating cigarette consumption as a function of both cigarette and beer prices. Adding the beer price to the demand equation only slightly changes the own price elasticity (0.32 here compared to -0.36 in Table 7). Overall, price responsiveness is smaller for cigarettes than it is for alcohol and, in particular, the smoking participation decision is far less elastic than the alcohol participation decision. Interestingly, increases in the price of beer are associated with decreases in cigarette consumption - the elasticity of cigarette consumption with respect to the price of beer is approximately 0.14 , which is about the same as the average cross price elasticity between cigarettes and the price of beer, wine and spirits found by J ones [1989]. This seems like a sizeable cross price effect, indicating that the effect of a one percent change in the price of a six-pack of beer has about 43 percent of the effect of a one percent price in the price of cigarettes themselves.

In contrast to our results on own price elasticity, we find that women's cigarette consumption is more sensitive to the price of beer than is men's cigarette consumption, a finding consistent with Kenkel [1993]. This may reflect greater prevalence of "social smoking and drinking" among women than among men. (Recall that overall, drinking is less important among women - 43 percent of females have had a drink compared to 60 percent of males, and that female drinkers drink less than male drinkers). It is possible that the overall cross price elasticity of -0.14 is mostly due to the effect of beer price on cigarette consumption among heavy drinkers who are also very likely to smoke. Other work has documented that the own price elasticity of alcohol is significantly negative for heavy drinkers.

The second two columns of Table 9 present a smoking participation equation and cigarette consumption equation for smokers only. A gain, the smoking participation equation is estimated using a linear probability model. The estimates indicate that smoking participation is more sensitive to own price 
than is the amount smoked among smokers. That is, participation is more price elastic than quantity consumed. This is consistent with the findings of L ewit and Coate [1982] and W asserman et al. [1991], among others.

Turning to the cross price effects, increasing the price of beer reduces smoking participation. Thus, higher beer prices not only lead to decreases in beer consumption, but also lead some smokers to quit smoking. The effect of alcohol prices on smoking participation is especially profound among women - a one percent rise in the price of beer induces a greater decline in smoking participation than does a 1 percent rise in the price of cigarettes. Although highly speculative, this finding accords with the popular notion of women as "social smokers". N ew data sets now emerging distinguish between "occasional smoking" and "daily smoking," presenting the future opportunity to explore this finding further, a path that we encourage given our work here. A mong those who continue to smoke, however, our results indicate that increases in beer prices increase cigarette consumption, reflecting substitutability (consistent with the "oral drive" explanation), although the effect is much smaller in magnitude than the effect on participation. Since the relationship between smoking participation and beer prices is stronger than the relationship between smoking consumption and beer prices, the overall effect of an increase in beer prices in the first column shows complementarity between cigarettes and beer, consistent with J ones.

The asymmetry in the cross-price elasticities of demand is somewhat perplexing, suggesting the importance of further work testing the validity of assumed symmetry. Although economic theory indicates that the cross price elasticities should be the same, our overall cross price elasticities are of opposite signs -the cross price elasticity of demand for cigarettes with respect to the price of beer is -.14 while the cross price elasticity of alcohol with respect to the price of cigarettes is .50. The asymmetry is largely due to differences in the price responsiveness of the participation decisions. While the cross price elasticities of the conditional demand equations are all positive (indicating substitution), the .39 cross price elasticity of drinking participation contrasts sharply with the -. 19 cross price elasticity of smoking participation, indicating complementarity. Note that although Goel and M orey (1995) find symmetric, positive cross 
prices, the estimated magnitudes are substantially different. They view this as potential evidence of differences in social norms regarding smoking and drinking, a view with which we concur.

Specifically, Goel and M orey write:

"... one might expect there to be some asymmetry in the numbers of people who smoke and drink liquor and those who only smoke or only drink liquor. In particular, it may be that the intersection of smokers and liquor drinkers constitutes a much larger proportion of the population of liquor drinkers than it does of the smoking population. Although we can find no empirical evidence or studies of this issue to support an assumption of this kind, our results are consistent with an explanation based upon this idea, namely, the cross-price elasticity (on cigarette price) in the liquor equation (0.332) is indeed larger than the cross price elasticity (on liquor price) in the cigarette equation (0.100)." (page 456)

In our work, we find that an F-test rejects the symmetry of the cross-price elastictities, suggesting the importance of further work on this issue, perhaps exploring the different groups as above.

While investigating the underlying behavioral processes determining drinking and smoking decisions is outside the scope of this paper, the measured elasticities are consistent with the following scenario. Increases in beer prices lead some to stop drinking (say, to not go to a bar after work) and as the "situational cue" for social smoking is eliminated, their smoking participation also declines. The effect of cigarette price on drinking participation follows a different scenario. Increases in cigarette prices lead some to quit smoking, inducing greater stress among the now-former smokers who turn to alcohol consumption for its palliative effects. While these scenarios are consistent with the estimates, additional econometric work is required to tease out their validity. ${ }^{24}$

\section{Conclusions}

This paper contributes to the limited econometric literature examining the interdependence of demand for cigarettes and alcohol using an under-utilized individual level data set. We believe that this work is an important initial step in investigating the complex interrelationships between cigarette and alcohol

\footnotetext{
24 As an example, because of the importance of the participation decisions in understanding the cross price effects, an important extension of this work would be to formulate and estimate a model of the joint participation decision.
} 
consumption, and suggests that further work is clearly warranted given the importance of understanding consumption of these items to pressing policy questions. Our work here suggests that introducing the price of beer into cigarette demand equations has little impact on the estimated own price elasticities, although introducing cigarette prices into alcohol demand equations increases the estimated ow $n$ price responsiveness of alcohol. Thus, increasing taxes on cigarettes may have a larger affect on consumption of "sins" than the elasticities based on ignoring the cross price effects indicate.

Overall, increasing the price of cigarettes appears to increase both the prevalence of drinking and the amount consumed by drinkers; increasing the price of beer increases smoking among smokers, but decreases smoking participation. We find that most of the price response (both own and cross prices) derives from changes in smoking and drinking participation, rather than changes in consumption among those who continue to smoke and drink. Interestingly, while alcohol and cigarettes are shown to be substitutes in the consumption equations, increases in the price of cigarettes increase drinking participation while increases in the price of alcohol decrease smoking participation. Additional econometric work is required to investigate the validity of this explanation for the results presented here. 


\section{References}

A merican Chamber of Commerce Researchers A ssociation, Inter-City C ost of Living Index, various years.

Becker, Gary S. and M urphy, Kevin M. [1988], "A Theory of Rational A ddiction. " Journal of Political Economy, A ugust 1988, 96, 4, 675-700.

Bobo, Gilchrist, Schilling, N oach and Schinke [1987], "Cigarette Smoking Cessation A ttempts by Recovering A lcoholics" Addictive Behaviors, 8, 209-215

Bien, Thomas H. and Roann Burge [1990], "Smoking and Drinking: A Review of the Literature," The International Journal of the Addictions, V ol. 25, No. 12, pp.1429-1431.

Browning, M artin [1987] "Eating, D rinking, Smoking and Testing the Life-cycle H ypothesis," Quarterly Journal of Economics p. 329-345.

Chaloupka, Frank [1992], "Clean Indoor Air Laws, A ddiction and Cigarette Smoking," A pplied Economics, Vol. 24, pp. 193-205.

and A dit L aixuthai [1997], "Do Y ouths Substitute A Icohol and M arijuana? Some Econometric Evidence," Eastern Economic Journal, Vol. 23, No. 3, pp. 253-76.

Cordes, Joseph J., Eric M. Nicholson and Frank J. Sammartino [1990], "Raising Revenue By Taxing A ctivities With Social Costs," National Tax Journal, Vol. X L III (3), September, pp. 343-356.

Craig and $\mathrm{V}$ an $\mathrm{N}$ atta [1977] "The A ssociation of Smoking and D rinking Habits in a Community Sample".J ournal of Studies on Alcohol, 38, 1434-1439

Evans, William N. and M atthew C. Farrelly [1998], "The Compensating Behavior of Smokers: Taxes, Tar and Nicotine," RAND Journal of Economics, Vol. 29, No. 3, pp. 578-95.

Goel, Rajeev K., and M athew J. M orey [1995] "T he Interdependence of Cigarette and Liquor Demand," Southern Economic Journal, Vol. 62, N o. 2, October, pp. 451-459.

Grossman, M ichael, Frank Chaloupka and Ismail Sirtalan [1998], "An Empirical A nalysis of Alcohol Addiction: Results From the Monitoring the Future Panels," Economic Inquiry, Vo. 36, No. 1, pp. 39-48.

Jones, A ndrew M. [1989], "A Systems A pproach To The Demand For A Icohol and Tobacco," Bulletin of Economic Research, Vol. 41, No. 2, A pril, pp. 85-105.

Kenkel, D onald S. [1993], "Drinking, Driving, and Deterrence: The Effectiveness and Social Costs of Alternative Policies," Journal of Law and Economics, Vol. XXXVI, N o. 2, October, pp. 877913.

Leung, Siu Fai and Charles Phelps [1993], "'M y Kingdom for a D rink . . . ?' A Review of Estimates of the Price Sensitivity of Demand for Alcoholic Beverages," National Institute of Health Publication N 0. 93-3513, pp. 1-31. 
L ewit, E ugene M . and Douglas C oate [1982], "The Potential for U sing Excise Taxes To Reduce Smoking," Journal of Health Economics, Vol. 1, pp. 121-145.

M anning, W illard G., Linda Blumberg and Lawrence H. M oulton [1995], "The Demand for A Icohol: The Differential Response to Price," Journal of Health Economics, V ol. 14, pp. 123-148.

Rosen, Harvey S. [1995], Public Finance, Fourth Edition, Irwin.

Serdula, M ary, W illiamson, David F, Kendrick, Juliette S., A nda, Robert F ., and Tim Byers, [1991] "Trends in Alcohol Consumption by Pregnant Women" The Journal of the A merican M edical Association, Vol. 265, No. 7.

Smith, Perry F., Patrick L. Remington, David F. Williamson and Robert F. A nda [1990], "A Comparison of A lcohol Sales Data with Survey Data or Self-Reported Alcohol U se in 21 States," A merican J ournal of Public Health, Vol. 80, N o. 3, M arch, pp. 309-312.

The Tobacco Institute, The Tax Burden on Tobacco: Historical Compilation 1993, V ol. 28, January 1994.

U.S. Bureau of Economic A nalysis, Survey of Current Business, various years.

U.S. Department of Commerce, County and City Data Book, 1994, 12th edition.

Viscusi, W. Kip [1992], Smoking: Making the Risky Decision, N ew Y ork, Oxford U niversity Press.

Walton [1972], "Smoking and A Icoholism: A Brief Report." A merican Journal of Psychiatry, $128,139-140$.

Warner, Kenneth E. [1978], "Possible Increases in the U nderreporting of Cigarette Consumption," Journal of the A merican Statistical A ssociation, Vol. 73, No. 362, pp. 314-318.

W asserman, J effrey, W illard G. M anning, Joseph P. N ewhouse and J ohn D. Winkler [1991], "The Effects of Excise Taxes and R egulations on Cigarette Smoking, " J ournal of Health Economics, Vol. 10, pp. 43-64. 
Table 1: Alcohol and Cigarette Consumption

Descriptive Statistics

\begin{tabular}{|c|c|c|c|}
\hline & Entire Sample & Women & Men \\
\hline \multicolumn{4}{|l|}{ Drinking } \\
\hline Drinks Per Month & $\begin{array}{c}10.73 \\
(25.81)\end{array}$ & $\begin{array}{c}5.73 \\
(14.74)\end{array}$ & $\begin{array}{c}17.37 \\
(34.44)\end{array}$ \\
\hline Drinker & $\begin{array}{c}0.503 \\
(0.500)\end{array}$ & $\begin{array}{c}0.431 \\
(0.495)\end{array}$ & $\begin{array}{c}0.600 \\
(0.500)\end{array}$ \\
\hline Drinks Per Month Among Drinkers & $\begin{array}{c}21.31 \\
(33.13)\end{array}$ & $\begin{array}{c}13.30 \\
(20.08)\end{array}$ & $\begin{array}{c}28.97 \\
(40.52)\end{array}$ \\
\hline \multicolumn{4}{|l|}{ Smoking } \\
\hline Cigarettes Per Day & $\begin{array}{c}4.60 \\
(9.78)\end{array}$ & $\begin{array}{c}3.97 \\
(8.70)\end{array}$ & $\begin{array}{c}5.44 \\
(11.00)\end{array}$ \\
\hline Smoker & $\begin{array}{c}0.249 \\
(0.432)\end{array}$ & $\begin{array}{c}0.235 \\
(0.424)\end{array}$ & $\begin{array}{c}0.267 \\
(0.442)\end{array}$ \\
\hline Cigarettes Per Day Among Smokers & $\begin{array}{c}18.49 \\
(11.30)\end{array}$ & $\begin{array}{c}16.85 \\
(10.22)\end{array}$ & $\begin{array}{c}20.42 \\
(12.16)\end{array}$ \\
\hline
\end{tabular}

This table reports means from the BRFSS data 1985-1993, excluding New Jersey, the District of Columbia, Hawaii, Maine and Rhode Island. There are 474,096 observations. Standard deviations are in parentheses. 
Table 2: Independent $V$ ariables

Descriptive Statistics

\begin{tabular}{|c|c|c|}
\hline V ariable & M ean & Standard Deviation \\
\hline Beer Price (\$ per six-pack) & 2.77 & 0.27 \\
\hline Cigarette Price (\$ per pack) & 1.17 & 0.16 \\
\hline Income (\$, thousands) & 23.31 & 16.97 \\
\hline Female & 0.571 & 0.500 \\
\hline Age & 44.58 & 17.44 \\
\hline $\mathrm{Age}^{2}$ & 2291.85 & 1749.06 \\
\hline \multicolumn{3}{|l|}{ Race } \\
\hline Black & 0.078 & 0.269 \\
\hline Other & 0.068 & 0.251 \\
\hline \multicolumn{3}{|l|}{ Education } \\
\hline High School Graduate & 0.359 & 0.480 \\
\hline Some College & 0.228 & 0.419 \\
\hline College Graduate & 0.239 & 0.427 \\
\hline \multicolumn{3}{|l|}{ Marital Status } \\
\hline N ever M arried & 0.182 & 0.386 \\
\hline Divorced & 0.115 & 0.320 \\
\hline Separated & 0.025 & 0.156 \\
\hline Widowed & 0.106 & 0.307 \\
\hline \multicolumn{3}{|l|}{ Region } \\
\hline North East & 0.115 & 0.319 \\
\hline N orth Central & 0.296 & 0.456 \\
\hline South & 0.349 & 0.477 \\
\hline \multicolumn{3}{|c|}{$\begin{array}{l}\text { This table reports means from the BRFSS data } 1985-1993 \text {, excluding N ew Jersey, the District of Columbia, } \\
\text { Hawaii, M aine and Rhode Island. There are } 474,096 \text { observations. All dollar values are adjusted for cross- } \\
\text { sectional variation in price levels, using a cost of living index from the A merican Chamber of Commerce } \\
\text { Researchers A ssociation (A CCRA), and are converted to } 1984 \text { dollars using the Consumer Price Index. The } \\
\text { omitted category for race is 'white', for education is 'Iess than high school', for marital status is 'married', and } \\
\text { for region is 'W est'. }\end{array}$} \\
\hline
\end{tabular}


Table 3: Alcohol and Cigarette Consumption Over Time

\begin{tabular}{ccccccc}
\hline Y ear & $\begin{array}{c}\text { Number } \\
\text { of States }\end{array}$ & $\mathrm{N}$ & $\begin{array}{c}\text { Drinking } \\
\text { Participation }\end{array}$ & $\begin{array}{c}\text { Alcohol } \\
\text { Consumption } \\
\text { A mong Drinkers }\end{array}$ & $\begin{array}{c}\text { Smoking } \\
\text { Participation }\end{array}$ & $\begin{array}{c}\text { Cigarette } \\
\text { Consumption } \\
\text { A mong Smokers }\end{array}$ \\
\hline 1985 & 23 & 20596 & 0.54 & 27.15 & 0.28 & 19.57 \\
1986 & 26 & 26487 & 0.54 & 26.63 & 0.28 & 19.33 \\
1987 & 33 & 39063 & 0.53 & 25.49 & 0.27 & 19.24 \\
1988 & 37 & 44391 & 0.52 & 24.78 & 0.26 & 18.94 \\
1989 & 40 & 52966 & 0.49 & 20.92 & 0.25 & 18.78 \\
1990 & 45 & 64258 & 0.50 & 19.66 & 0.24 & 18.56 \\
1991 & 48 & 68299 & 0.48 & 20.00 & 0.24 & 18.29 \\
1992 & 49 & 76666 & 0.49 & 19.76 & 0.24 & 18.12 \\
1993 & 50 & 81370 & 0.51 & 17.95 & 0.23 & 17.41 \\
\hline
\end{tabular}

BRFSS data 1985-1993, excluding New Jersey, the District of Columbia, Hawaii, M aine and Rhode Island. 
Table 4: Smoking and Drinking Participation

\begin{tabular}{|c|c|c|c|}
\hline & \multicolumn{2}{|c|}{ Smoking Prevalence } & \multirow[b]{2}{*}{ Non-D rinkers } \\
\hline & Entire Sample & D rinkers & \\
\hline Entire Sample & $24.9 \%$ & $29.1 \%$ & $20.6 \%$ \\
\hline Women & $23.5 \%$ & $29.0 \%$ & $19.4 \%$ \\
\hline \multirow[t]{3}{*}{ M en } & $26.7 \%$ & $29.1 \%$ & $23.0 \%$ \\
\hline & \multicolumn{2}{|c|}{ Drinking Prevalence } & \\
\hline & Entire Sample & Smokers & Non-Smokers \\
\hline Entire Sample & $50.3 \%$ & $58.8 \%$ & $47.5 \%$ \\
\hline W omen & $43.1 \%$ & $53.1 \%$ & $40.0 \%$ \\
\hline M en & $60.0 \%$ & $65.5 \%$ & $58.0 \%$ \\
\hline
\end{tabular}

BRFSS data 1985-1993, excluding N ew Jersey, the District of Columbia, Hawaii, M aine and Rhode Island. There are 474,096 observations. 
Table 5: Cigarette and A Icohol Consumption Own Price Estimates

\begin{tabular}{|c|c|c|c|c|}
\hline \multirow{2}{*}{$\begin{array}{l}\text { Independent } \\
\text { V ariables }\end{array}$} & \multicolumn{2}{|c|}{ Alcohol Consumption } & \multicolumn{2}{|c|}{ Cigarette Consumption } \\
\hline & $\begin{array}{l}\text { Parameter } \\
\text { Estimate }\end{array}$ & $\begin{array}{l}\text { Standard } \\
\text { Error }\end{array}$ & $\begin{array}{l}\text { Parameter } \\
\text { Estimate }\end{array}$ & $\begin{array}{c}\text { Standard } \\
\text { Error }\end{array}$ \\
\hline Own Price & -2.960 & 0.158 & -1.422 & 0.123 \\
\hline Income & 0.087 & 0.003 & -0.025 & 0.001 \\
\hline F emale & -11.186 & 0.075 & -1.716 & 0.123 \\
\hline Age & -0.047 & 0.013 & 0.397 & 0.005 \\
\hline A ge Squared & -0.001 & 0.0001 & -0.005 & 0.0001 \\
\hline $\begin{array}{l}\text { Race (relative to white) } \\
\text { Black }\end{array}$ & -3.235 & 0.139 & -2.764 & 0.053 \\
\hline Other & -1.798 & 0.147 & -2.049 & 0.056 \\
\hline $\begin{array}{l}\text { Education (relative to < high school) } \\
\text { High School Graduate }\end{array}$ & 0.903 & 0.110 & -1.207 & 0.042 \\
\hline Some College & 0.828 & 0.123 & -2.483 & 0.047 \\
\hline College Graduate & 0.172 & 0.128 & -4.388 & 0.049 \\
\hline $\begin{array}{l}\text { M arital Status (relative to married) } \\
N \text { ever } M \text { arried }\end{array}$ & 6.349 & 0.112 & 0.366 & 0.043 \\
\hline Divorced & 6.270 & 0.120 & 2.821 & 0.046 \\
\hline Separated & 5.554 & 0.236 & 2.523 & 0.090 \\
\hline W idowed & 3.309 & 0.149 & 1.172 & 0.057 \\
\hline $\begin{array}{l}\text { Year (relative to 1985) } \\
1986\end{array}$ & -0.086 & 0.230 & -0.013 & 0.088 \\
\hline 1987 & -1.371 & 0.213 & -0.246 & 0.082 \\
\hline 1988 & -2.217 & 0.210 & -0.321 & 0.082 \\
\hline 1989 & -4.646 & 0.204 & -0.378 & 0.082 \\
\hline 1990 & -5.308 & 0.199 & -0.574 & 0.080 \\
\hline 1991 & -4.841 & 0.198 & -0.498 & 0.085 \\
\hline 1992 & -5.027 & 0.195 & -0.587 & 0.085 \\
\hline 1993 & -5.561 & 0.194 & -0.946 & 0.080 \\
\hline R-Squared & 0.079 & & 0.071 & \\
\hline
\end{tabular}

This table presents ordinary least squares estimates from the BRFSS data, 1985-1993, excluding N ew Jersey, the District of Columbia, Hawaii, M aine and R hode Island. There are 474,096 observations. All dollar values are adjusted for cross-sectional variation in price levels, and are converted to 1984 dollars using the Consumer Price Index. Regressions include region effects. 
Table 6: Alcohol and Cigarette Consumtpion

Own Price Elasticities

With and W ithout State Effects

\begin{tabular}{|c|c|c|c|c|}
\hline & \multicolumn{2}{|c|}{ Region Effects } & \multicolumn{2}{|c|}{ State E ffects } \\
\hline & $\begin{array}{l}\text { Parameter } \\
\text { Estimates }\end{array}$ & $\begin{array}{l}\text { Estimated } \\
\text { Elasticities }\end{array}$ & $\begin{array}{l}\text { Parameter } \\
\text { Estimates }\end{array}$ & $\begin{array}{l}\text { Estimated } \\
\text { Elasticities }\end{array}$ \\
\hline \multicolumn{5}{|l|}{ Alcohol } \\
\hline Beer Price & $\begin{array}{l}-2.960 \\
(0.158)\end{array}$ & -0.76 & $\begin{array}{l}-0.083 \\
(0.250)\end{array}$ & -0.02 \\
\hline Income & $\begin{array}{c}0.087 \\
(0.003)\end{array}$ & 0.19 & $\begin{array}{c}0.081 \\
(0.003)\end{array}$ & 0.18 \\
\hline R-Squared & 0.079 & & 0.084 & \\
\hline \multicolumn{5}{|l|}{ Cigarettes } \\
\hline Cigarette Price & $\begin{array}{l}-1.422 \\
(0.123)\end{array}$ & -0.36 & $\begin{array}{l}-0.038 \\
(0.211)\end{array}$ & -0.01 \\
\hline Income & $\begin{array}{l}-0.025 \\
(0.001)\end{array}$ & -0.13 & $\begin{array}{l}-0.026 \\
(0.001)\end{array}$ & -0.13 \\
\hline R-Squared & 0.071 & & 0.073 & \\
\hline
\end{tabular}

This table presents ordinary least squares estimates from the BRFSS data, 1985-1993, excluding N ew J ersey, the District of Columbia, Hawaii, M aine and Rhode Island. There are 474,096 observations. All dollar values are adjusted for cross-sectional variation in price levels, and are converted to 1984 dollars using the Consumer Price Index. A lthough not reported, controls for age, race, educational attainment, marital status and year effects were estimated. Standard errors are in parentheses. 
Table 7: Cigarette and A lcohol Consumption

Own Price Elasticities for Women and $M$ en

\begin{tabular}{|c|c|c|c|c|}
\hline \multirow{2}{*}{ V ariable } & \multicolumn{2}{|c|}{ Alcohol Consumption } & \multicolumn{2}{|c|}{ Cigarette Consumption } \\
\hline & $\begin{array}{l}\text { Parameter } \\
\text { Estimates }\end{array}$ & $\begin{array}{l}\text { Estimated } \\
\text { Elasticities }\end{array}$ & $\begin{array}{c}\text { Parameter } \\
\text { Estimates }\end{array}$ & $\begin{array}{l}\text { Estimated } \\
\text { Elasticities }\end{array}$ \\
\hline \multicolumn{5}{|l|}{ Whole Sample } \\
\hline Own Price & $\begin{array}{l}-2.960 \\
(0.158)\end{array}$ & -0.76 & $\begin{array}{l}-1.422 \\
(0.123)\end{array}$ & -0.36 \\
\hline Income & $\begin{array}{c}0.087 \\
(0.003)\end{array}$ & 0.19 & $\begin{array}{l}-0.025 \\
(0.001)\end{array}$ & -0.13 \\
\hline R-squared & 0.079 & & 0.071 & \\
\hline \multicolumn{5}{|l|}{ Women } \\
\hline Own Price & $\begin{array}{l}-2.114 \\
(0.123)\end{array}$ & -1.03 & $\begin{array}{l}-1.099 \\
(0.146)\end{array}$ & -0.32 \\
\hline Income & $\begin{array}{c}0.074 \\
(0.002)\end{array}$ & 0.28 & $\begin{array}{l}-0.023 \\
(0.001)\end{array}$ & -0.11 \\
\hline R-squared & 0.042 & & 0.066 & \\
\hline \multicolumn{5}{|l|}{ Men } \\
\hline Own Price & $\begin{array}{l}-4.047 \\
(0.329)\end{array}$ & -0.64 & $\begin{array}{l}-1.869 \\
(0.211)\end{array}$ & -0.48 \\
\hline Income & $\begin{array}{c}0.090 \\
(0.005)\end{array}$ & 0.14 & $\begin{array}{l}-0.030 \\
(0.002)\end{array}$ & -0.17 \\
\hline R-squared & 0.036 & & 0.072 & \\
\hline
\end{tabular}

This table presents ordinary least squares estimates from the BRFSS data 1985-1993, excluding New Jersey, the District of Columbia, $\mathrm{H}$ awaii, $\mathrm{M}$ aine and Rhode Island. There are 474,096 observations in the entire sample, 270,758 on women and 203,338 on men. All dollar values are adjusted for cross-sectional variation in price levels, and are converted to 1984 dollars using the Consumer Price Index. A lthough not reported, controls for age, race, educational attainment, marital status, region and year effects were estimated. Standard errors are in parentheses. 
Table 8: Alcohol Consumption

Own and Cross Price Effects

\begin{tabular}{|c|c|c|c|c|c|c|}
\hline \multirow{2}{*}{$\begin{array}{l}\text { Variable } \\
\text { Whole Sample }\end{array}$} & \multicolumn{2}{|c|}{ Drinks Per Month } & \multicolumn{2}{|c|}{ Drinking Participation } & \multicolumn{2}{|c|}{$\begin{array}{l}\text { Drinks Per Month } \\
\text { Among Drinkers }\end{array}$} \\
\hline & & & & & & \\
\hline Beer Price & $\begin{array}{l}-3.762 \\
(0.170)\end{array}$ & -0.97 & $\begin{array}{l}-0.132 \\
(0.003)\end{array}$ & -0.73 & $\begin{array}{l}-1.800 \\
(0.301)\end{array}$ & -0.23 \\
\hline Cigarette Price & $\begin{array}{l}4.600 \\
(0.347)\end{array}$ & 0.50 & $\begin{array}{l}0.169 \\
(0.006)\end{array}$ & 0.39 & $\begin{array}{l}2.223 \\
(0.622)\end{array}$ & 0.12 \\
\hline Income & $\begin{array}{l}0.086 \\
(0.003)\end{array}$ & 0.19 & $\begin{array}{l}0.004 \\
(0.00005)\end{array}$ & 0.19 & $\begin{array}{l}0.020 \\
(0.004)\end{array}$ & 0.02 \\
\hline R-squared & 0.080 & & 0.148 & & 0.079 & \\
\hline \multicolumn{7}{|l|}{ Women } \\
\hline Beer Price & $\begin{array}{l}-2.663 \\
(0.131)\end{array}$ & -1.29 & $\begin{array}{l}-0.137 \\
(0.004)\end{array}$ & -0.88 & $\begin{array}{l}-1.151 \\
(0.270)\end{array}$ & -0.31 \\
\hline Cigarette Price & $\begin{array}{l}3.122 \\
(0.268)\end{array}$ & 0.64 & $\begin{array}{l}0.193 \\
(0.009)\end{array}$ & 0.52 & $\begin{array}{l}1.162 \\
(0.557)\end{array}$ & 0.10 \\
\hline Income & $\begin{array}{l}0.074 \\
(0.002)\end{array}$ & 0.28 & $\begin{array}{l}0.005 \\
(0.0006)\end{array}$ & 0.25 & $\begin{array}{l}0.033 \\
(0.004)\end{array}$ & 0.04 \\
\hline R-squared & 0.042 & & 0.142 & & 0.020 & \\
\hline \multicolumn{7}{|l|}{ Men } \\
\hline Beer Price & $\begin{array}{l}-5.154 \\
(0.351)\end{array}$ & -0.82 & $\begin{array}{l}-0.125 \\
(0.005)\end{array}$ & -0.58 & $\begin{array}{l}-2.133 \\
(0.526)\end{array}$ & -0.20 \\
\hline Cigarette Price & $\begin{array}{l}6.421 \\
(0.721)\end{array}$ & 0.43 & $\begin{array}{l}0.139 \\
(0.010)\end{array}$ & 0.27 & $\begin{array}{l}3.239 \\
(1.090)\end{array}$ & 0.13 \\
\hline Income & $\begin{array}{l}0.089 \\
(0.005)\end{array}$ & 0.13 & $\begin{array}{l}0.003 \\
(0.00007)\end{array}$ & 0.13 & $\begin{array}{l}0.005 \\
(0.008)\end{array}$ & 0.004 \\
\hline R-squared & 0.036 & & 0.101 & & 0.041 & \\
\hline
\end{tabular}

This table presents ordinary least squares estimates from the BRFSS data 1985-1993, excluding New Jersey, the District of Columbia, Hawaii, Maine and Rhode Island. There are 474,096 observations in the entire sample, 270,758 on women and 203,338 on men. All dollar values are adjusted for cross-sectional variation in price levels, and are converted to 1984 dollars using the Consumer Price Index. Although not reported, controls for age, race, educational attainment, marital status, region and year effects were estimated. Standard errors are in parentheses below parameter estimates. Elasticities are in bold type to the right of the parameter estimates. 
Table 9: Cigarette Consumption

Own and Cross Price Effects

\begin{tabular}{|c|c|c|c|c|c|c|}
\hline \multirow{2}{*}{$\begin{array}{l}\text { Variable } \\
\text { Whole Sample }\end{array}$} & \multicolumn{2}{|c|}{ Cigarettes Per Day } & \multicolumn{2}{|c|}{ Smoking Participation } & \multicolumn{2}{|c|}{$\begin{array}{l}\text { Cigarettes Per Day } \\
\text { Among Smokers }\end{array}$} \\
\hline & & & & & & \\
\hline Beer Price & $\begin{array}{l}-0.226 \\
(0.065)\end{array}$ & -0.14 & $\begin{array}{l}-0.017 \\
(0.003)\end{array}$ & -0.19 & $\begin{array}{l}0.301 \\
(0.146)\end{array}$ & 0.04 \\
\hline Cigarette Price & $\begin{array}{l}-1.256 \\
(0.132)\end{array}$ & -0.32 & $\begin{array}{l}-0.038 \\
(0.006)\end{array}$ & -0.18 & $\begin{array}{l}-2.213 \\
(0.299)\end{array}$ & -0.14 \\
\hline Income & $\begin{array}{l}-0.025 \\
(0.001)\end{array}$ & -0.13 & $\begin{array}{l}-0.001 \\
(0.00004)\end{array}$ & -0.09 & $\begin{array}{l}-0.007 \\
(0.002)\end{array}$ & -0.01 \\
\hline R-squared & 0.071 & & 0.071 & & 0.110 & \\
\hline \multicolumn{7}{|l|}{ Women } \\
\hline Beer Price & $\begin{array}{l}-0.273 \\
(0.077)\end{array}$ & -0.16 & $\begin{array}{l}-0.019 \\
(0.004)\end{array}$ & -0.22 & $\begin{array}{l}0.269 \\
(0.183)\end{array}$ & 0.04 \\
\hline Cigarette Price & $\begin{array}{l}-0.899 \\
(0.146)\end{array}$ & -0.23 & $\begin{array}{l}-0.029 \\
(0.008)\end{array}$ & -0.14 & $\begin{array}{l}-1.884 \\
(0.375)\end{array}$ & -0.13 \\
\hline Income & $\begin{array}{l}-0.023 \\
(0.001)\end{array}$ & -0.11 & $\begin{array}{l}-0.001 \\
(0.0001)\end{array}$ & -0.09 & $\begin{array}{l}-0.008 \\
(0.003)\end{array}$ & -0.01 \\
\hline R-squared & 0.066 & & 0.069 & & 0.081 & \\
\hline \multicolumn{7}{|l|}{ Men } \\
\hline Beer Price & $\begin{array}{l}-0.146 \\
(0.110)\end{array}$ & -0.09 & $\begin{array}{l}-0.012 \\
(0.004)\end{array}$ & -0.12 & $\begin{array}{l}0.294 \\
(0.233)\end{array}$ & 0.04 \\
\hline Cigarette Price & $\begin{array}{l}-1.753 \\
(0.226)\end{array}$ & -0.45 & $\begin{array}{l}-0.049 \\
(0.009)\end{array}$ & -0.22 & $\begin{array}{l}-2.564 \\
(0.477)\end{array}$ & -0.15 \\
\hline Income & $\begin{array}{l}-0.030 \\
(0.002)\end{array}$ & -0.17 & $\begin{array}{l}-0.002 \\
(0.0001)\end{array}$ & -0.19 & $\begin{array}{l}-0.006 \\
(0.004)\end{array}$ & -0.02 \\
\hline R-squared & 0.072 & & 0.075 & & 0.102 & \\
\hline
\end{tabular}

This table presents ordinary least squares estimates from the BRFSS data 1985-1993, excluding New Jersey, the District of Columbia, Hawaii, Maine and Rhode Island. There are 474,096 observations in the entire sample, 270,758 on women and 203,338 on men. All dollar values are adjusted for cross-sectional variation in price levels, and are converted to 1984 dollars using the Consumer Price Index. Although not reported, controls for age, race, educational attainment, marital status, region and year effects were estimated. Standard errors are in parentheses below parameter estimates. Elasticities are in bold type to the right of the parameter estimates. 